\title{
Characterization of giant mottled eel (Anguilla marmorata) gastrointestinal tract that origin from Thua Thien Hue, Vietnam.
}

\author{
Kieu Thi Huyen ${ }^{1}$, Nguyen Quang Linh ${ }^{2 *}$ \\ ${ }^{1}$ Faculty of Fisheries, University of Agriculture and Forestry, Hue University, Thua Thien Hue, Hue City 530000, Vietnam \\ ${ }^{2}$ Department of Nutritional Diseases and Systems for Livestock and Aquaculture, Institute of Biotechnology, Hue \\ University, Thua Thien Hue, Hue City 530000, Vietnam
}

\begin{abstract}
This study investigated the dietary component and morphology of the digestive tract of Anguilla marmorata during its yellow stages (non-migrants). A total of 127 samples, ranging in total length from 17-108 $\mathrm{cm}$ and weight from 10-3200 $\mathrm{g}$ were collected from Thua Thien Hue, Vietnam. The structure of the gastrointestinal tract indicated that Anguilla marmorata has the typical characters of carnivorous fish such as a wide mouth, small teeth in bands; free tongue; short esophagus, stomach, and intestines made up of folds. The mouth size of Anguilla marmorata ranged from 1.81-6.6 cm and it increased with the body weight of fish. Anguilla marmorata is an animal-eating species with an RLG (relative length of the gut) ranging from 0.34 to 0.41 (RLG <1). Crustacea is the preferred food of eels with the highest proportion of the number, weight, and frequency of crustaceans in the gastrointestinal tract with $65 \%, 64 \%$, and $80 \%$, respectively. Crustacea was also the most important food of Anguilla marmorata in the wild with the index of relative importance $($ IRI\% $\%)=79 \%$. Correlation equation between length $(\mathrm{L}=17$ $108 \mathrm{~cm})$ and weight $(\mathrm{W}=10-3200 \mathrm{~g})$ of Anguilla marmorata is $\mathrm{L}=9.948 \mathrm{~W}^{0.0622}$ with correlation coefficient $\mathbf{R}^{2}=0.93$. Our report provides new dietary information about $A$. marmorata that is useful in nutrition planning and aquaculture potential.
\end{abstract}

Keywords: Teeth, Mouth size, Intestine, IRI\%, Carnivorous fish.

Accepted on October 23, 2019

\section{Introduction}

There are 16 species and 3 subspecies of freshwater eels in the world [1,2]. Anguilla marmorata has a wide distribution throughout most of the tropical and subtropical western-central Pacific and Indian Oceans and associated freshwater systems. This species is a highly prized as commercial food fish. Once the fish has achieved yellow and silver life stages, the species could succumb to overfishing. Additional fishing pressure of A. marmorata could origin from seed-stock for farming [3]. The yellow eel growth stage may be as short as two to three years in warm productive habitats, but about six to 20 years or more in more northerly latitudes, e.g. in the Pearl River, China [4]. Female eels that have reached the age of sexual maturity will swim downstream in large groups to lower stream areas or to the river mouth to meet up with the male eels and then they will travel all the way to deep ocean sea areas for mating and spawning [5]. A. marmorata has been found in the deep sea areas south of the Philippines, eastern Indonesia, and Papua New Guinea. After spawning, the adults die, and the eggs then drift along to the ocean. The young hatch as a white, weakly shaped eel with the appearance a leaf. When they arrive at the coast they transform into an infant eel with a, short round body. This stage of development is sometimes called the eagle stage. Following further development they move into streams to live in fresh water [6].
The nutritional habits of eel will be change by living conditions and migration patterns in their life cycle. The feeding ecology of eel is not similar in different species. The feeding ecology of some tropical species of eel still remains almost completely unknown while temperate species have been best described. The four most well-investigated eel species are Anguilla anguilla, Anguilla rostrata, Anguilla dieffenbachii, and Anguilla australis and of these, A. anguilla is the only best described species [7]. Since the 1930s, the commercial and cultural aspects have without a doubt been the most important drivers of interest in attaining knowledge on the feeding ecology of the different life-stages of freshwater eels [8,9]. Nevertheless, the current knowledge-base largely relates to the yellow eel stage of Anguilla eels and the feeding ecology of the larval stage (leptocephali) is still poorly understood [10,11]. The severe decline in freshwater eel populations over the last 30 years or more $[12,13]$ provided an additional important driver for need to establish knowledge on their feeding ecology. Resh et al. [14] investigated the diet of A. marmorata and A. obscura in Rivers in the tidal zone in Moorea Island, French Polynesia. The low number of individuals studied does not allow for any firm conclusions to be drawn on their diet [14]. A study of Butler and Marshall [15] demonstrated that A. labiata in the upper Kairezi River, Zimbabwe predominantly fed on freshwater crustaceans [15]. 
In Vietnam, studies indicate that there are four species of eel in the Anguilla group. A. marmorata, A. japonica, A. bicolor pacifica, A. bornesensis [16]. According to Phu [17], many species of eel are widely distributed and have economic value to fisher man particularly in the provinces from Quang Tri to Khanh Hoa [17]. In Thua Thien Hue, A. marmorata is one of two Anguilla species identified by $[18,19]$ base on morphological characteristics analyzed. Anguilla marmorata is also widely distributed, exploited and cultivated with high economic value. However, the understanding of the nutritional characteristics of Anguilla marmorata have not been conducted in Vietnam. Here we report new information on the natural diet of Anguilla marmorata at the yellow stage to clarify the nutritional and growth characteristics of the eel in the wild. Our report provides new dietary information about $A$. marmorata that is useful in nutrition planning and aquaculture. The results of these studies will provide the basis for the development of more efficient reproduction, nursing, and aquaculture processes.

\section{Material and Methods}

There were 127 marbled eels (Anguilla marmorata) collected from the study areas in Thua Thien Hue (Table 1) with sizes from (total length range) and having weights ranging 10 $\mathrm{g}$ to $3200 \mathrm{~g}$ (Table 2) when the eels were gathered in July and August 2018.

After collection, the specimens were stored in cold water $\left(15^{\circ} \mathrm{C}\right)$ before incubation at $-30^{\circ} \mathrm{C}$ to prevent the food contents of the digestive tract from being decomposed. The anatomy of the eel's digestive system such as the mouth, teeth, esophagus, stomach, intestines, were observed and described basic characteristics and images of them. The natural diet was determined by the morphological characteristics and composition of foods in the gastrointestinal tract. The samples were divided into 4 groups to characterize their diets (Table 2).

The ratio of gut length and standard length was calculated according to the formula of Al-Hussainy: RLG $=\mathrm{Li} / \mathrm{L}$. The size of eel mouth were measured and calculated according to the formula proposed by Shirota: $\mathrm{MH}=\mathrm{AB} * \sqrt{2}$ with $\mathrm{AB}$ is the upper jaw length $(\mathrm{mm}), \mathrm{MH}$ is the mouth size when opening $90^{\circ}$ (mm) [20].

Table 1. The number of samples collected.

\begin{tabular}{|c|l|c|c|}
\hline No. & Locations & Number of samples & Ratio \% \\
\hline 1 & Thao Long Dam & 26 & 20 \\
\hline 2 & Truoi Dam & 18 & 14 \\
\hline 3 & Cua Lac Dam & 15 & 12 \\
\hline 4 & Nam Dong district & 16 & 13 \\
\hline 5 & PhongDien district & 28 & 22 \\
\hline 6 & PhuLoc district & $\mathbf{2 4}$ & 19 \\
\hline & Total & $\mathbf{1 2 7}$ & $\mathbf{1 0 0}$ \\
\hline
\end{tabular}

Table 2. Distribution of samples by weight.

\begin{tabular}{|c|c|c|}
\hline Group & Weight $(\mathbf{g})$ & Number of samples \\
\hline 1 & $10-100$ & 32 \\
\hline 2 & $101-500$ & 35 \\
\hline 3 & $501-1000$ & 30 \\
\hline 4 & $1001-3200$ & 30 \\
\hline
\end{tabular}

J Fish Res 2019 Volume 3 Issue 2
The food contents of the fish intestinanal tract was observed using a magnifying glass or microscope. The feed ingredients were classified into 4 groups: fish, crustaceans, mollusca, and others (organic sludge and unidentified) based on methods inthe published literature [16].

In order to determine the role of foods by different size groups, we used some approaches such as the numerical and weight methods described by Biswas [21], combined with frequency appearing method as described by Hynes [22]. At the same time, the index of relative importance (IRI\%) was also used. The IRI\% provides the correlation coefficient percentage of a food group with the total correlation coefficient calculated by the following formula [23]:

$$
\operatorname{IRI} I_{i} \%=\frac{I R I_{i}}{\sum_{i=1}^{n} I R I_{i}} \times 100
$$

The IRI is the relative index of each feed group for the study population and the index was calculated by the formula: IRI = (N\%+W\%) x O\%. In which, $\mathrm{N} \%$ is the percentage by number of each food group within the digestive tract, $\mathrm{W} \%$ is the percentage by weight of each food group in the digestive tract and $\mathrm{O} \%$ is the appearing frequency of each food in intestine.

In addition, the correlation between length and weight was calculated by the formula of Beverton - Holt: $\mathrm{W}=\mathrm{a}$ $L^{b}$. With, "W" is total body weight of eel $(\mathrm{g})$, "L" is total body length of eel $(\mathrm{cm})$, "a" is the initial growth constant, "b" is the growth factor [24].

All data in this study was collected, analyzed and evaluated by Microsoft Excel 2016 software.

\section{Results and Discussion}

\section{Morphological characteristics of the Anguilla marmorata digestive system}

Morphology of the mouth and teeth: The eel's mouth is long and pointed, thick lips, a long mouth incision. The lower jaw has a larger size than the upper jaw. The free tongue does not stick to the bottom of the mouth with an oval shape (Figure 1). The composition of the teeth is one of the indicators showing the eating habits of fish. Eel teeth are pointed, shaped like dog teeth, placed on the jaw and the main oral cavity forming strips. Upper maxillary teeth are arranged like arrows while lower jaw include two rows of pointed teeth with spaces larger than the upper maxillary (Figure 2).

Characteristics of the digestive organs: The esophagus is a continuous section of the mouth cavity. The junction of the esophagus and stomach is usually unclear. The esophagus moves food down to the stomach. The esophagus of most fish is short. Different fish species have varyingdegrees of esophagus elasticity [24]. The eel's esophagus is tubular, short, thickwalled, the inside with many folds and good elasticity.

The liver is the largest digestive gland of fish. The important task of the liver is secretion of blue-green bile into the gallbladder and the small intestine through the bile duct, while the liver is also a detoxification organ of fish. The liver of eel is large, dark brown to light reddish brown, located at the top of the internal cavity. The gall bladder is separated from the liver, 

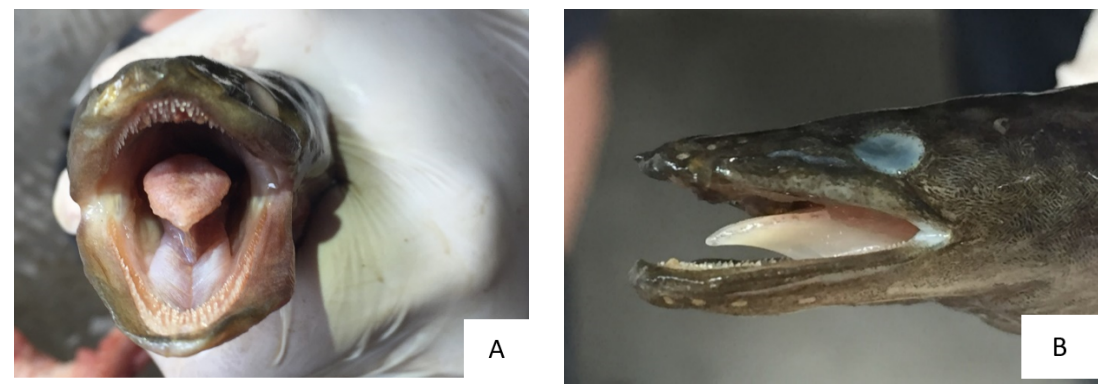

Figure 1. Morphology of mouth and tongue. (A - Vertical form; B - Horizontal shape)
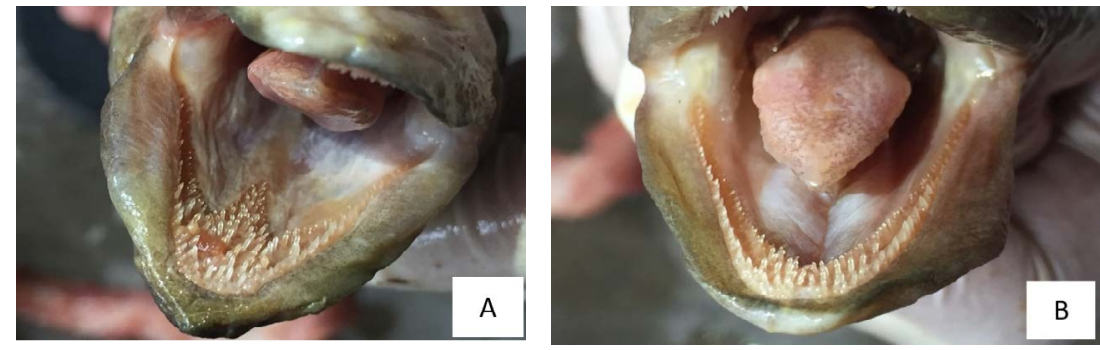

Figure 2.Morphology of teeth. ( $A$ - Upper jaw; $B$ - Lower jaw)

located below the liver and covered by esophagus and stomach. The gall bladder is large, oval in shape, dark brown in color contains yellow-green bile. The gall bladder is connected with the stomach by a duct from the liver and a tube down to the front of the intestine (Figure 3).

The stomach is located next to the esophagus. The task of the stomach is to contain food and digestive enzymes involved in the digestive process of food. The stomach usually has a relationship with food and size of prey. Large stomach fishes are capable of eating large prey species and vice versa [25]. The stomach of the eel has a large bag shape with a thick wall, and the inside has many folds to create high elasticity that allows the stomach to accept large food items as contents. The intestine is the end piece of the digestive tract that terminates with the anus. The task of the intestine is food fermentation and digestion using enzymes from digestive glands. Digested food is then absorbed as nutrients into the bloodstream. The eel's intestine is tubular, folded and relatively short. The intestinal wall is thick with many folds on the inside (Figure 3).

The mouth reaches to under the rear edge of the eyes with a projecting lower jaw and a visible patch that conspicuously narrows in its middle on the roof of the mouth. Other characteristics include thick lips and minute teeth in bands separated by a toothless groove on the upper jaw separating the inner and outer teeth [26]. Loan Nguyen Bach, described it as a large-sized fish with large sharp doglike teeth [27,28]. According to Yen MD, et al. [29], animal-eating species often have a large mouth size, pointed teeth in two jaws, ploughshare, and palatine. They have a short intestine and stomach separated from intestinal bundles. There for, the structural characteristics of A. marmorata's digestive system have been described as consistent with a carnivorous species.

\section{Change of mouth size and the ratio of intestinal length and body length}

Changes of mouth size of Anguilla marmorata: The fish's

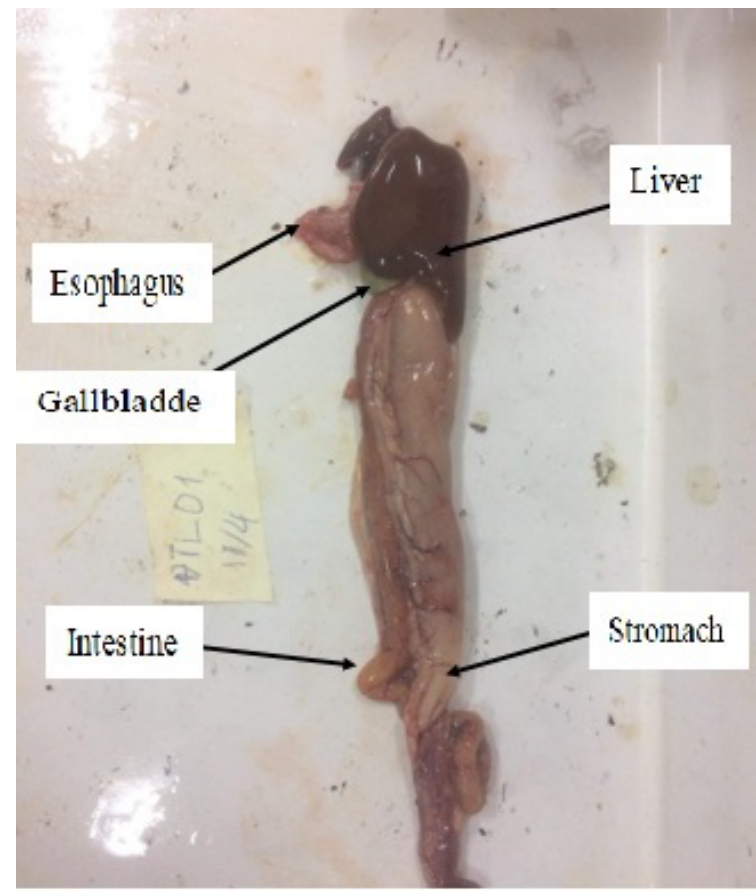

Figure 3. Morphylogy of the digestive organ.

mouth size influences its feeding habit where prey-to-mouth size of $45 \%$ is maximum entry limit [20,30]. For eels, fish mouth size increases with the development of the fish. Fish weighing from 10 to $100 \mathrm{~g}$ have mouth size is $1.81 \mathrm{~cm}$ corresponding to the body length of $28.18 \mathrm{~cm}$. The mouth size of eel increased significantly when its weight reaches between 101-500 g. For instance, an eel measuring $45.63 \mathrm{~cm}$ has mouth size of $3.21 \mathrm{~cm}$. The eel with body weight from 501 to $1000 \mathrm{~g}$ has mouth size was $4.53 \mathrm{~cm}$. When reaching the weight of 1001-3200 g, the mouth size of the eel was $6.6 \mathrm{~cm}$ with an average body length of $96 \mathrm{~cm}$ (Table 3 ).

The ratio of intestine length and total length (RLG): The results in Table 4 show that the value of RLG index of Anguilla marmorata with weights ranging from 10 to $3200 \mathrm{~g}$ ranges from 
Citation: Huyen KT, Linh NQ. Characterization of giant mottled eel (Anguilla marmorata) gastrointestinal tract that origin from Thua Thien Hue, Vietnam.. J Fish Res. 2019;3(2):4-9.

Table 3. The mouth size of eel by size groups.

\begin{tabular}{|c|c|c|c|}
\hline Group & Length $\mathbf{( c m )}$ & Upper jaw length $\mathbf{( c m )}$ & Mouth size $\mathbf{( c m})$ \\
\hline 1 & $28.18 \pm 6.137$ & $1.28 \pm 0.318$ & $1.81 \pm 0.449$ \\
\hline 2 & $45.63 \pm 6.431$ & $2.27 \pm 0.399$ & $3.21 \pm 0.564$ \\
\hline 3 & $60.75 \pm 0.829$ & $3.20 \pm 0.122$ & $4.53 \pm 0.173$ \\
\hline 4 & $96.00 \pm 16.971$ & $4.67 \pm 0.544$ & $6.60 \pm 0.769$ \\
\hline
\end{tabular}

Table 4. RLG value of eel.

\begin{tabular}{|c|c|c|c|}
\hline Group & Total length & Intestinal length & RLG \\
\hline 1 & $28.18 \pm 6.137$ & $9.54 \pm 2.126$ & $0.34 \pm 0.041$ \\
\hline 2 & $45.63 \pm 6.431$ & $16.99 \pm 3.831$ & $0.37 \pm 0.059$ \\
\hline 3 & $60.75 \pm 0.829$ & $23.88 \pm 5.572$ & $0.39 \pm 0.095$ \\
\hline 4 & $96.00 \pm 16.971$ & $39.50 \pm 7.778$ & $0.41 \pm 0.073$ \\
\hline
\end{tabular}

0.34 to $0.41(\mathrm{RLG}<1)$ and increases by body weight. The lowest value of RLG is 0.34 that belong to the size group of 100 to 250 $\mathrm{g}$. The RLG value of 2 groups: $251-500 \mathrm{~g}$ and $501-1000 \mathrm{~g}$ are 0.37 and 0.39 respectively. The RLG value of the $>1000 \mathrm{~g}$ group is the highest at 0.41 .

According to Biswas, individuals in the same species differ in the RLG index depending on the stage of development of the fish [21]. According to Smith, the gut length depends on the age and nature of the food they consume, the length of the bowel increases with the increase in the proportion of plant foods in the fish diet. Girgis (linked by Liem PT and Dinh TD) also argues that the RLG value is low at the juvenile stage and high at the adult stage [24]. During growth, the digestive tract of the fish will increase in length and increase the folds to digest and absorb nutrients, which leads to increased RLG values [28]. In addition, animal-eating fish (carnivorous) usually have the value of RLG is $\leq 1$, omnivorous fish have the value of RLG from 1 to 3 and that for plant-eating fish (herbivorous) is $>3$ [31], indicating that Anguilla marmorata is a carnivorous fish.

\section{The composition and role of natural foods in gastrointestinal tract of Anguilla marmorata}

The composition of natural foods in the eel's gastrointestinal tract: The figures from Table 5 indicated that the number of crustaceans (shrimps, crabs) in the eel's gastrointestinal tract accounts for the highest proportion of all food groups $(65 \%)$, which tends to increase with the development of fish from $53 \%$ to $75 \%$. Fish is the second largest component that accounts for $21 \%$ of the digestive tract content of eels and fish prey decrease over the developmental stages (down from $29 \%$ to $15 \%$ ). The same trend was observed with the mollusca group with a gradual decrease of $12 \%$ to $5 \%$. Other components show very low amounts containing only $5 \%$.

At the same time, the results of a survey on the weight of the feeding groups in the eel's gastrointestinal tract showed that crustaceans were the largest weight, accounting for from 59\% to $75 \%$ of total diets (average of $64 \%$ ). Fish prey accounted for an average of $29 \%$ of total weight feed (from $17 \%$ to $33 \%$ ). Molluscas and others occupy only small amounts in the gastrointestinal tract of eels with $5 \%$ and $2 \%$, respectively (Table 5).

In addition, the values in Table 5 also show that the frequency of crustaceans is the highest in the eel's natural diet with an average of $80 \%$ for all of the group size. In each group, the frequency of crustaceans was also higher than that of other foods, especially in the group of 101-500 g, where the frequency of crustaceans was up to $93 \%$. Fish is the second most frequently occurring food in the gastrointestinal tract with a mean value of $49 \%$ in all groups. Molluscas has an average occurrence frequency of $24 \%$ and tends to decrease with the development of eels. Other types of food such as soil, roots, garbage, cannot be digested and remain intact in the intestinal tract; this group only appears about $12 \%$. This is not the food that fish prefer, and it is only eaten at random during the ingestion of other foods.

The role of foods in the eel's gastrointestinal tract: The data from Table 6 shows that the value of IRI\% for crustacea is highest in the digestive tract of eel with an average of $79 \%$ in all size groups. This value tends to increase with the development of fish. Fish are the second most important food in the gut of the eel with a mean IRI\% of $18 \%$. Mollusca have a much lower value than crustaceans and fish, while IRI\% is only $2 \%$. The

Table 5. The composition of food in the gastrointestinal tract of eel (\%).

\begin{tabular}{|c|c|c|c|c|c|c|c|c|c|c|c|c|}
\hline \multirow{3}{*}{ Group } & \multicolumn{12}{|c|}{ Species of foods } \\
\hline & \multicolumn{3}{|c|}{ Crustacea } & \multicolumn{3}{|c|}{ Fish } & \multicolumn{3}{|c|}{ Mollusca } & \multicolumn{3}{|c|}{ Others } \\
\hline & $\mathbf{N}_{f}$ & $W_{f}$ & $F_{f}$ & $N_{f}$ & $W_{f}$ & $F_{f}$ & $N_{f}$ & $w_{f}$ & $F_{f}$ & $N_{f}$ & $w_{f}$ & $F_{f}$ \\
\hline 1 & 53 & 59 & 71 & 29 & 28 & 57 & 12 & 6 & 29 & 6 & 6 & 14 \\
\hline 2 & 65 & 61 & 93 & 20 & 32 & 47 & 11 & 5 & 27 & 4 & 2 & 13 \\
\hline 3 & 67 & 75 & 88 & 21 & 17 & 63 & 6 & 5 & 25 & 6 & 4 & 13 \\
\hline 4 & 75 & 61 & 64 & 15 & 33 & 36 & 5 & 4 & 18 & 5 & 2 & 9 \\
\hline Average & 65 & 64 & 80 & 21 & 29 & 49 & 9 & 5 & 24 & 5 & 2 & 12 \\
\hline
\end{tabular}

Note: Nf: The amount of the number of foods in the gastrointestinal tract; Wf: The amount of the weight of foods in the gastrointestinal tract; Ff: the frequency of food in the digestive tract.

Table 6. Correlation index (IRI\%) of foods in the gastrointestinal tract.

\begin{tabular}{|c|c|c|c|c|}
\hline \multirow{2}{*}{ Group } & \multicolumn{3}{|c|}{ Species of food } \\
\cline { 2 - 5 } & Crustacea & Fish & Mollusca & Others \\
\hline 1 & 67 & 27 & 3 & 1 \\
\hline 2 & 80 & 17 & 2 & 1 \\
\hline 3 & 82 & 16 & 2 & 1 \\
\hline 4 & 81 & 16 & $\mathbf{2}$ & 1 \\
\hline
\end{tabular}




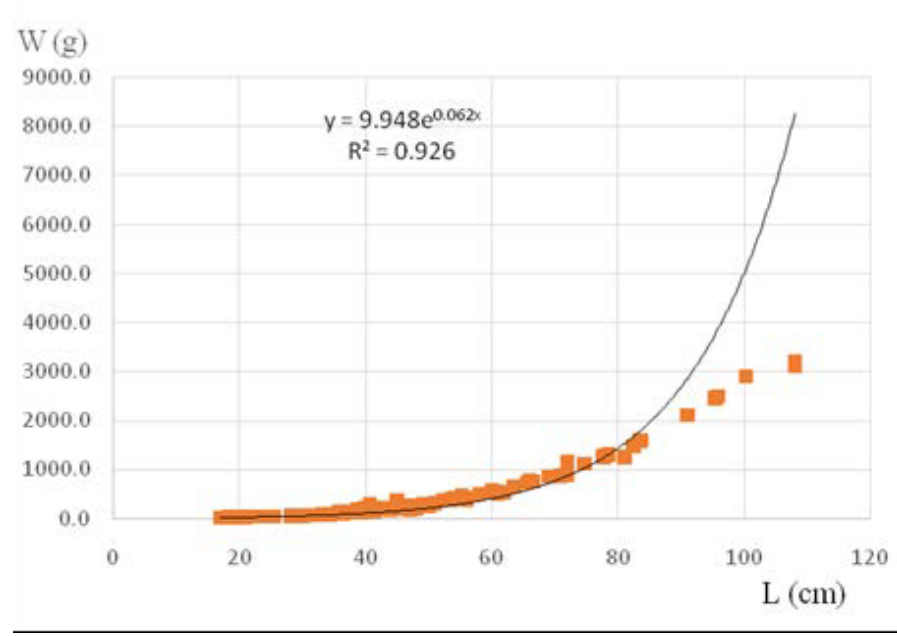

Figure 4. The correlation between length and weight.

role of other foods is negligible (1\%). There is no significant difference in the role of foods in the gastrointestinal tract of each size group. Thus, crustacean food is the most important item in the gastrointestinal tract of Anguilla marmorata.

\section{Correlation between body length and weight}

Growth is the process of increasing body size and weight; this process is characteristic of individual fish species and is expressed by the length and weight correlation of fish [31]. The correlation between total length and body weight of eel is shown in Figure 4.

The correlation equation between length $(\mathrm{L}=17-108 \mathrm{~cm})$ and weight $(\mathrm{W}=10-3200 \mathrm{~g})$ of 127 individuals of Anguilla marmorata was $\mathrm{L}=9.948 \mathrm{~W}^{0.0622}$ with a correlation coefficient $\mathrm{R}^{2}=0,93$. A value of $\mathrm{R}^{2}=0.9083$ was obtained in the range of 10 to $3200 \mathrm{~g}$ indicating a strong correlation between length and weight of Anguilla marmorata. A correlation coefficient $\mathrm{R}^{2}>0.9$ is very high [32]. A. marmorata grow rapidly in terms of body length during development until their body mass reaches 2000 $\mathrm{g}$, the length growth tends to slow down. In addition, during the evolution of the eel from 7-3200 $\mathrm{g}$, fish became less rotund as length increases $(b<3)$.

\section{Conclusion}

Morphological characteristics of the gastrointestinal tract show that Anguilla marmorata is a carnivorous fish. They have a long and pointed mouth, the sharp of teeth look like a dog arranged on two jaws and the main oral bones and free tongue. The eel has a large mouth size, varying by body weight. The larger the fish, the larger the size of the mouth. The size of the mouth of eel ranged from 1.81 to $6.6 \mathrm{~cm}$ in the mass range of $10-3200 \mathrm{~g}$.

The stomach and intestines of Anguilla marmorata are short, with many folds having great elasticity. The RLG value of Anguilla marmorata fluctuates between 0.34 and 0.41 and less than 1 , which is characteristic for fish-eating species.

The eel's natural feed ingredients include crustaceans, fish, mollusks, and other species. Crustaceans are the most abundant species in the gastrointestinal tract, with $68 \%$ of the number, $64 \%$ of weight, $80 \%$ of frequency and $79 \%$ for IGI $\%$ index.
Correlation equations between length $(\mathrm{L}=17-108 \mathrm{~cm})$ and weight $(\mathrm{W}=10-3200 \mathrm{~g})$ from 127 individuals in this study of Anguilla marmorata were $\mathrm{L}=9.948 \mathrm{~W}^{0.0622}$ with correlation coefficient $\mathrm{R}^{2}=0.9083$ indicating a strong correlation between length and weight. The growth rate of the length tends to decrease with the increase in body weight.

\section{Acknowledgement}

This study was financially supported by $\mathrm{PhD}$ scholarship 2018 of Southeast Asian Regional Center for Graduate Study and Research in Agriculture (SEARCA) College, Los Baños, Laguna 4031, Philippines and Hue University (No. DHH201902-113), 03 Le Loi, Vinh Ninh, Hue city, Thua Thien Hue, Vietnam.

\section{References}

1. Ege V. A revision of the genus Anguilla shaw, a systematic, phylogenetic and geographical study. Dana Rep. 1939;16:1256.

2. Watanabe S, Aoyama J, Tsukamoto K. A new species of freshwater eel Anguilla luzonensis (Teleostei: Anguillidae) from Luzon island of the Philippines. Fish Sci. 2009;75:387-92.

3. Jacoby D, Gollock M. Anguilla marmorata. The IUCN red list of threatened species. 2014.

4. Williamson GR, Boëtius J. The eels Anguilla Marmorata and A. Japonica in the Pearl river, China, and Hong Kong. Asian Fisheries Science. 1994;6:129-138.

5. McCosker JE, Bustamante RH, Wellington GM. The freshwater eel, Anguilla marmorata, discovered at Galapagos. Noticias de Galapagos. 2003;62:2-6.

6. Rainboth WJ. Fishes of the cambodian mekong. FAO Species identification field guide for fishery purposes. FAO. Rome. 1996.

7. Takaomi Arai. Biology and ecology of Anguillid eels. Taylor \& Francis Group. CRC Press. 2016.

8. Godfrey H. Feeding of eels in four new Brunswick salmon streams. Progress Reports for the Atlantic Stations. Biological Station St. Andrews. Ottawa. 1957.

9. Tesch FW. The Eel. 3rd Edn. Blackwell Science Ltd. Oxford. United Kingdom. 2003.

10. Terahara TS, Chow HK, Lee SH, et al. Efficiency of peptide nucleic acid-directed PCR clamping and its application in the investigation of natural diets of the Japanese eel Leptocephali. PlosONE. 2011;6:e25715.

11. Miller MJ, Chikaraishi Y, Ogawa NO, et al. A low trophic position of japanese eel larvae indicates feeding on marine snow. Biol Lett. 2013;9(1):20120826.

12. Moriarty C, Dekker W. Management of the European eelenhancement of the European eel fishery and conservation of the species. Irish Fisheries Bulletin. Dublin. 1997;15.

13. Dekker W. What caused the decline of the Lake IJsselmeer Eel stock after 1960. ICES J Mar Sci. 2004;61:394-404. 
14. Resh VH, Moser M, Poole M. Feeding habits of some freshwater fishes in streams of Moorea, French Polynesia. Annls Limnol. 1999;35(3):205-10.

15. Butler JRA, Marshall BE. Resource use within the crabeating guild of the upper Kairezi River. Zimbabwe. J Trop Ecol. 1996;12:475-90.

16. Yen MD, Duc NH. Freshwater fish families in northern provinces of Vietnam. Science and Technology Publishing House. Hanoi. 1987.

17. Phu VV. Species composition of the fish and biological characteristics of 10 economic fish species in Thua Thien Hue Lagoon. National University. Hanoi. 1995.

18. Phu VV. Species composition of the fish in Thua Thien Hue Lagoon. Journal of Biology. 1997;19(2):14-22.

19. Phu VV, Thuan ND. Fish composition of O Lau River, Thua Thien Hue Province. Journal of Research and Development. 2009;55:61-71.

20. Shirota A. Studies on the mouth size of fish larvae. Nippon Suisan Gakkaishi. 1970;36:353-68.

21. Biswas SP. Manual of method in fish biology. South Asian Publishers Pvt. Ltd. New Delhi. India. 1993.

22. Hynes HB. The food of freshwater sticklebacks (Gasterosterus aculeatus and Pygosteus pungitius), with a review of the methods used in studies of the food of the fishes. J Anim Ecol. 1950;19:36-58.
23. Enric Cortes. A critical review of methods of studying fish feeding based on analysis of stomach contents: application to elasmobranch fishes. Can J Fish Aqua Sci. 1996;54:726-738.

24. Liem PT, Dinh TD. Fish biology research methods. Chapter 4: Fish nutrition research methods. Can Tho University. 2004.

25. Smith DG. Anguillidae. Freshwater eels. FAO species identification guide for fishery purposes. The living marine resources of the western central pacific. FAO. Rome. 1999;3:1630-6.

26. Jacoby D, Gollock M. Anguilla marmorata. The IUCN red list of threatened species. 2014.

27. Loan NB. Classification and biological characteristics of freshwater fish species in the lower Mekong river, Vietnam. Cantho University. 1998.

28. Loan NB. Curriculum I. Can Tho University. 2004.

29. McCosker, Yen MD. Aquaculture. Publisher of University and Secondary School. 1979;390p.

30. Cunha I, Planas M. Optimal prey size for early turbot larvae (Scophthalmus Maximus) base on mouth and ingested prey size. Aquaculture. 1999;175:103-110.

31. Nikolsky GV. Ecology of fishes. Academic Press. London. $1963 ; 352$.

32. Giap, Dang V. Analysis of scientific data by MS-Excel. The Education Publishing House. 2007.

\section{*Correspondence to:}

Nguyen Quang Linh

Institute of Biotechnology

Hue University

Thua Thien Hue,

Hue City 530000,

Vietnam

E-mail: nguyenquanglinh@hueuni.edu.vn 